FEAP User Guide 98/77

May 1998

\title{
User Guide for Remote Monitoring Equipment for Cathodic Protection Systems: Phase II
}

\author{
by \\ Vicki L. Van Blaricum \\ U.S. Army Construction Engineering Research Laboratories \\ Champaign, IL 61826-9005
}

Approved for Public Release; Distribution is Unlimited. 


\section{SF 298}

Cathodic protection (CP) is required by Federal regulation or Army policy on many buried and submerged structures to prevent corrosion. Periodic testing is required to ensure proper $\mathrm{CP}$ system operation, but this testing can be timeconsuming and many Army Directorates of Public Works (DPWs) do not have the resources to perform it.

Several companies have begun manufacturing remote monitoring units (RMUs) for CP systems. These units allow DPWs to monitor multiple CP systems from a central location. Several commercially available units have been evaluated during a two-phase FEAP demonstration. Beneficial RMU features have been identified and lessons have been learned concerning their implementation. A FEAP User Guide (FEAP UG 97/75) was published based on the results from Phase I. This user guide provides updated information based on Phase II results. 


\section{Foreword}

This study was conducted for the U. S. Army Center for Public Works under the Facilities Engineering Application Program (FEAP); Work Unit F17, "Demonstration of Remote Monitoring for Cathodic Protection Systems." The technical monitor was Malcolm McLeod, CECPW-ES.

The work was performed by the Materials Science and Technology Division (FLM) of the Facilities Technology Laboratory (FL), U.S. Army Construction Engineering Research Laboratories (USACERL). The USACERL Principal Investigator was Vicki L. Van Blaricum. Ilker R. Adiguzel is Acting Chief, CECER-FL-M; and L. Michael Golish is Acting Operations Chief, CECER-FL. The USACERL technical editor was Gordon L. Cohen, Technical Information Team.

Special appreciation is expressed to Mr. J oseph Ogiba and Mr. Thomas Ferguson, Directorate of Public Works, Fort Drum, NY, for their invaluable and enthusiastic support of this demonstration.

COL J ames A. Walter is Commander of USACERL and Dr. Michael J . O'Connor is Director. 


\section{Contents}

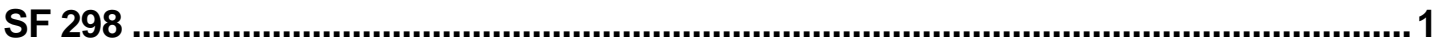

Foreword

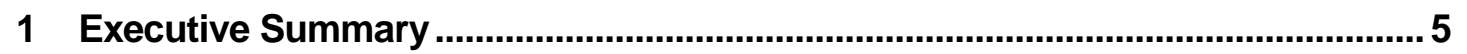

2 Pre-Acquisition .......................................................................................................7

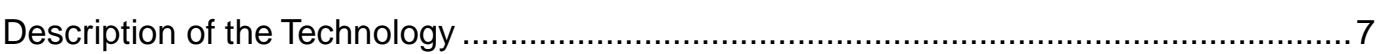

Life-Cycle Costs and Benefits ..................................................................................9

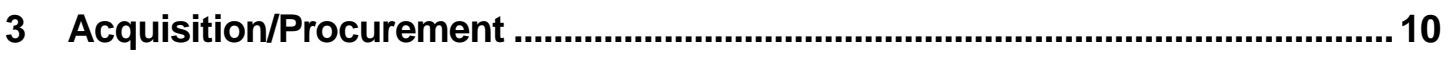

Potential Funding Sources .......................................................................................10

Technology Components and Sources .....................................................................10

Procurement Documents ................................................................................11

Procurement Scheduling ........................................................................................13

4 Post-Acquisition ...............................................................................................14

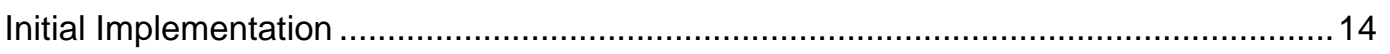

Operation and Maintenance of the Technology............................................................15

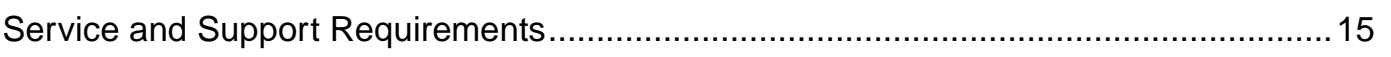

Performance Monitoring ...................................................................................15

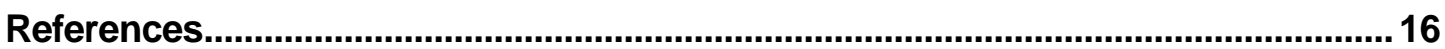

\section{Distribution}




\section{Executive Summary}

Cathodic protection (CP) is required by regulation and/or Army policy on many buried and submerged metallic structures to prevent corrosion. For example, the Code of Federal Regulations (CFR), Title 40, requires corrosion protection on all underground storage tanks (USTs) and associated piping by December 1998. Lack of manpower and money has made it difficult for Army Directorates of Public Works (DPWs) to perform the periodic testing that is required to ensure proper, ongoing $C P$ system operation. Many $C P$ system malfunctions remain undetected until the structure that was supposed to be protected corrodes and leaks.

Several companies manufacture remote monitoring units (RMUs) that are designed specifically to evaluate impressed current CP systems. These units can monitor multiple CP systems from a single DOS*-compatible computer. This master computer can be located anywhere on or off an installation - even thousands of miles away from the rectifiers and test sites. RMUs minimize the amount of time required for $\mathrm{CP}$ system evaluation because personnel do not need to visit the site unless a problem is detected. RMUs ther efore make it easier for Army installations to establish a regular CP testing program, and they make it possible to detect and repair CP system malfunctions quickly.

As part of its ongoing research and development in the area of corrosion prevention, the U.S. Army Construction Engineering Research Laboratories (USACERL) conducted a two-phase demonstration of remote CP monitoring technology under the Army's Facilities Engineering Applications Program (FEAP).

Phase I of the demonstration was conducted during Fiscal Years (FY) 1995 and 1996. RMUs from three manufacturers were evaluated, and the results showed that only one of the units tested was fully functional, operational, accurate, and reliable throughout the demonstration. A FEAP User Guide (FEAP UG 97/75)

* DOS: disk operating system. 
was published at the end of Phase I (Van Blaricum and Norris 1997). It is strongly recommended that the reader obtain a copy of the Phase I Guide to use in conjunction with this Phase II Guide because the Phase I Guide explains many of the basic issues involved in $\mathrm{CP}$ remote monitoring.

Several manufacturers introduced new RMUs onto the market too late to be evaluated during Phase I. Therefore, it was decided to conduct a second phase of the demonstration. Two new RMUs were evaluated during Phase II, and both were found to be reliable and acceptable for use on Army installations.

\section{Points of Contact:}

\section{Vicki Van Blaricum}

USACERL

ATTN : CECER-FL-M

P.O. Box 9005

Champaign, IL 61826-9005

217-373-6771 or 1-800-USA-CERL

Fax 217/373-6732

Mr. J oseph Ogiba

Directorate of Public Works

ATTN : AFZS-EH-OM

Bldg. 4000

Fort Drum, NY 13602-5097

315-772-3322

\section{Mr. Malcolm McLeod}

U. S. Army Center for Public Works

ATTN : CECPW-ES

7701 Telegraph Road

Alexandria, VA 22315-3862

703-806-5196

Fax 703/806-5216 


\section{Pre-Acquisition}

\section{Description of the Technology}

Cathodic protection regulations and guidance can be found in the following documents:

- 40 CFR Parts 280-281, Federal regulations for underground storage tanks and associated piping

- 49 CF R Parts 171-172, Federal regulations used as guidance by the Army for natural gas piping

- ETL 1110-3-474, Army guidance for various buried and submerged structures.

Lack of manpower and money has made it difficult for Army DPWs to perform the periodic CP system performance testing that is required by these documents. Consequently, many $\mathrm{CP}$ system malfunctions remain undetected until the structure that was supposed to be protected corrodes and leaks. In many cases the pipe or tank must be replaced prematurely and life-cycle costs are significantly increased.

Remote monitoring equipment allows personnel to collect CP performance data from distant locations using a single modem-equipped DOS-based personal computer. Personnel do not need to travel to field sites to take measurements. The collected data are stored on the computer and may be imported to a spreadsheet or other software for analysis.

CP RMUs can be used to measure and record the following parameters:

- structure-to-soil "on" potential

- structure-to-soil "instant-off" potential (IOP) 
- rectifier $\mathrm{DC}$ *oltage

- rectifier DC current

- rectifier $A C$ voltage.

Users who are unfamiliar with testing cathodic protection systems should consult Military Handbook 1004-10 or Air Force Manual 85-5. Other useful reference materials and standards are available from NACE I International, PO Box 218340, Houston, TX 77218-8340, phone 713-492-0535.

RMUs are typically installed near the CP rectifier, but may also be installed at critical structure-to-soil potential test stations. Manufacturers can provide units for either indoor or outdoor use. RMUs that are to be used for monitoring structure-to-soil potentials use a permanent reference electrode that is buried near the protected structure. Additional information on site selection and preparation can be found in the Phase I FEAP User Guide (Van Blaricum and Norris 1997).

A number of beneficial RMU system features have been identified throughout this FEAP demonstration. Features that are considered essential to reliable RMU operation are identified below. Features that are not critical to reliable operation, but that provide considerable convenience to the user are also identified. Complete definitions and discussions of these features can be found in the Phase I user guide. The features are:

- CP system independence (convenient for installations with several different makes and models of rectifiers)

- backup battery (essential)

- 100 percent solid state circuitry and industrial-grade components (essential)

- surge protection on all unit inputs and outputs, induding data channels, power supply, and telephone line (essential)

- full differential channel type (essential if several el ectrically isolated structures will be monitored using one RMU)

- ability to program the unit remotely (convenient)

- al arm feature (some users may consider this to be essential for critical structures)

\footnotetext{
* DC is direct current; $A C$ is alternating current.

* NACE: National Association of Corrosion Engineers.
} 
- synchronized rectifier interruption (essential for IOP readings from multiple rectifiers)

- relay that can function under the voltages, currents, and ambient conditions given for a specific application (essential for IOP readings; see Van Blaricum and Norris 1997)

- powerful data analysis software (convenient).

\section{Life-Cycle Costs and Benefits}

The main benefits to be achieved from CP remote monitoring include:

1. Cost and manpower demands associated with manual monthly rectifier and structure-to-soil potential tests can be avoided.

2. Continuous corrosion protection of structures can be readily maintained. CP system problems can be rapidly pinpointed and repaired.

3. Continuous CP results in longer life and fewer failures or repairs for protected structures. This results in overall lower life-cycle costs.

4. Documentation of CP system performance to meet regulatory or other recordkeeping requirements is simple and automated.

5. Sites that are remote or difficult to access physically can be monitored with ease. For example, large amounts of snow and very cold temperatures in the winter at Fort Drum, NY, make it extremely difficult to monitor outdoor rectifier sites.

Benefit 1 listed above can be quantified by comparing the cost of manual rectifier monitoring with the cost of remote monitoring. The annual cost of manual rectifier monitoring is avoided when RMUs are installed because the time to monitor a single site using an RMU is negligible (less than 5 minutes per month). A sample calculation for Fort Drum is included in the Phase I user guide (Van Blaricum and Norris 1997). 


\section{Acquisition/Procurement}

\section{Potential Funding Sources}

Army installations can use the Maintenance and Repair " $\mathrm{K}$ " account funds to procure the remote monitoring systems.

\section{Technology Components and Sources}

For typical applications, the required components are (1) the remote monitoring units/systems themselves, (2) permanent reference cells, and (3) a DOScompatible personal computer for data acquisition.

RMUs designed specifically for CP monitoring are currently available through several companies. The market is changing constantly due to advances in hardware and software technology. At the time of this writing, the following companies are known to produce and/or sell RMUs that are manufactured in the United States and have all or most of the beneficial features described previously:

M. C. Miller Company, Inc.

341 Margaret King Avenue

Ringwood, NJ 07456

Phone: $800-367-2238$

FAX: 201-728-5615

("DAX" system)
Metretek, Inc.

300 North Drive

Melbourne, FL 32934

Phone: 800-327-8559

FAX: 407-259-2900

(“CPM II" system)

JA Electronics Manufacturing, Inc.

P. O. Drawer 1187

10022 Mula Road

Stafford, TX 77477

Phone: 281-879-9903

FAX: 281-879-9913

("PAC3" system)

This list may not be all-inclusive. 
At the time of this writing, permanent copper-copper sulfate reference electrodes are known to be available from:

Electrochemical Devices, Inc.

P.O. Box 355

Belmont, MA 02178

Phone: (617)484-9085

FAX: (617)484-3923
Farwest Corrosion Control

17311 South Main Street

Gardenia, CA 90248-3105

Phone: 310-532-9524

This list may not be all-inclusive.

Most of the available systems require a DOS-compatible computer running Microsoft Windows 3.1 or later for data acquisition and analysis. The minimum recommended system configuration includes an 80486 processor with at least 4 $\mathrm{Mb}$ of random access memory (RAM) and at least $20 \mathrm{Mb}$ of free hard drive space. Some units require a Hayes-compatible modem, while others use a proprietary modem sold by the RMU manufacturer. A dedicated computer is not required, so most installations will be able to use computer resources al ready on hand.

Each RMU site must be wired with a standard telephone line for communication with the master computer. Some systems allow multiple units to be monitored from a single telephone line. Some units on the market can communicate by cellular phone, radio, or satellite, but these units were not evaluated in this FEAP demonstration.

Each RMU site must also be wired with AC power to operate the unit. Most units operate on standard 120 volts AC (VAC) current, but manufacturers can accommodate higher voltages at a site by installing a step-down transformer within the RMU enclosure at the time of manufacture. Therefore, the purchaser must specify the type of AC power available at each RMU site when the units are procured.

Installation and setup of CP remote monitoring systems (both hardware and software) may be done either by DPW personnel or contractors.

\section{Procurement Documents}

There are currently no Army or Corps of Engineers guidance documents that specifically address CP RMUs or permanent reference electrodes. Installation of CP RMUs should be conducted in accordance with the applicable sections of the National Electrical Code (NEC) and Corps of Engineers Guide Specification 
(CEGS) 16642, Cathodic Protection System, Impressed Current; CEGS 16415, Electrical Work, Interior; and CEGS 16375, Electrical Distribution System, Underground.

\section{Remote Monitoring Units}

Configurations of CP remote monitoring systems tend to vary widely. Some manufacturers provide the monitoring system in a single self-contained electrical enclosure while others use a modular approach involving several components and electrical enclosures. There is also a great deal of variation in cathodic protection rectifiers and other system components. Therefore, it is very important to work closely with the manufacturer during the procurement phase to make sure that they understand your specific requirements. If the manufacturer asks you a question about your CP system(s) that you do not understand, always ask for clarification. Clear communication is necessary to ensure that the manufacturer provides a monitoring system suitable for your CP system, and it can prevent a great deal of frustration after the system is installed.

Because of the wide range of possibilities, only general guidance is given here.

The manufacturer will ask for details about your CP system and the RMUs you wish to order. Some typical details you will need to provide include:

- AC voltage at the location where RMU is to be installed

- type of mounting hardware and enclosure required

- type of environment (e.g., indoor, outdoor, high-moisture, etc.)

- rectifier output voltage and current ratings

- location of shunt for rectifier current measurement (negative or positive output of rectifier)

- number of measurement channels needed

- whether or not you wish to take instant-off potential (IOP) readings using a relay to interrupt the current, and where you wish the relay to be located (AC input or DC output).

Important: Do not try to guess the answers to any of these questions. If you do not know or are not sure, it is generally worth the time and effort to travel to the proposed RMU site and obtain the information needed. 


\section{Reference Electrode}

A permanent copper-copper sulfate reference electrode should be installed with each remote monitoring system that will be used to monitor structure-to-soil potentials. Please note that these are not the same as the portable handheld reference electrodes used for manual CP system testing. Electrodes that meet the following guidelines will be suitable for most buried structures:

- copper-copper sulfate reference cell

- designed for permanent underground installation with a design life of at least 15 years

- consists of a saturated gelled copper-copper sulfate element surrounded in a prepackaged backfill mix that is designed to minimize migration of contaminants from the surrounding soil

- stability of \pm 5 millivol ts

- attached lead wire with high-molecular-weight polyethylene (HMWPE) insulation.

Be sure to determine how much lead wire is needed to reach from the reference cell to the RMU. Splicing or otherwise altering the manufacturer-supplied lead wire can result in inaccurate measurements. Most vendors have several standard lead wire lengths available, and they can generally provide custom lengths to meet your specific needs.

One reference electrode known to meet these requirements is the EDI Model URCUG-SW, which is available from the vendors listed previously. This is the reference cell that was used at all sites in the FEAP demonstration, but other suitable electrodes may be available.

\section{Procurement Scheduling}

Permanent reference electrodes are generally off-the-shelf items. CP RMUs are generally custom-built to the ordering agencyls specifications. For this reason, allow 2 to 3 months from the date of the order to the date of receipt. Additionally, as installation requires the burying of permanent reference cells, procurement should be scheduled so the units are installed when the ground is not frozen. Installation of permanent reference cells when the ground is frozen is not recommended. 


\section{Post-Acquisition}

\section{Initial Implementation}

The manufacturer's instructions should be followed carefully for the installation of all RMUs, reference cells, and software.

RMUs should be installed by an electrician, preferably one who is familiar with cathodic protection. Standard safety precautions for electrical work should be followed.

Reference cells should be buried at structure (pipe or tank) depth and approximately 12 to 24 in 2 away from the structure's surface. The reference cell wire should be routed to the location where the RMU will be installed. Do not install reference cells when the ground is frozen. Standard procedures and safety precautions for underground utility work should be followed.

RMU software should be installed on the computer that will be used to acquire data from the units. Most of the software for the FEAP-tested units is well documented, easy to use, and only requires basic familiarity with Microsoft Windows 3.1 or later.

Data may be acquired from the RMUs after all components are installed. Accuracy of the data from the RMU should be verified by comparing it with measurements taken using traditional manual methods of CP system testing. If any readings are inaccurate, follow the manufacturer's instructions for calibration or troubleshooting.

\footnotetext{
* 1 in. $=2.54 \mathrm{~cm}$.
} 


\section{Operation and Maintenance of the Technology}

For maximum benefit, CP performance data should be acquired and analyzed on a regular basis so any malfunctions can be pinpointed and repaired. The frequency of data acquisition will depend upon regulatory requirements, Army guidance, and local preferences. Data should be stored for future reference and analysis.

A properly installed RMU that meets the general guidelines discussed in this document should require little or no periodic maintenance. RMU backup batteries may need to be replaced if there is an extended power failure.

\section{Service and Support Requirements}

Implementation of this technology does not require special staffing. Data acquisition and analysis may be performed by an engineer, technician, or other qualified person who is familiar with the basics of CP system analysis.

Most manufacturers offer service and/or technical support packages for a fee.

\section{Performance Monitoring}

As noted previously, RMU performance and accuracy may be verified by comparing the RMU readings with measurements taken using traditional $\mathrm{CP}$ monitoring techniques. These readings should be taken as often as recommended by the manufacturer. Measurements that are inaccurate or that fall outside typical ranges of values indicate a cathodic protection problem that should be investigated. 


\section{References}

Air Force Manual 85-5, Maintenance and Operation of Cathodic Protection Systems (Headquarters, Department of the Air F orce, 9 February 1982).

Code of Federal Regulations (CFR), title 40, parts 280-281.

CFR, title 49, part 192.

Corps of Engineers Guide Specification (CEGS) 16642, Cathodic Protection System, I mpressed Current (Headquarters, U.S. Army Corps of Engineers [HQUSACE ], 1 October 1994).

CEGS 16415, Electrical Work, Interior (HQUSACE, 1 December 1991).

CEGS 16375, Electrical Distribution System, Underground (HQUSACE, 1 November 1992).

Engineer Technical Letter (ETL) 1110-3-474 (HQDA, 14 J uly 1995).

Military Handbook (MIL-HDBK) 1004/10, Electrical Engineering Cathodic Protection (Department of Defense, $31 \mathrm{~J}$ anuary 1990).

Van Blaricum, Vicki L. and William R. Norris, Remote Monitoring Equipment for Cathodic Protection Systems, FEAP U ser Guide 97/75 (U.S. Army Construction Engineering Research Laboratories, April 1997). 
USACERL DISTRIBUTION

Chief of Engineers

ATTN: CEHEC-IM-LH (2)

ATTN: CEHEC-IM-LP (2)

ATTN: CECC-R

ATTN: CECW

ATTN: CECW-O

ATTN: CECW-P

ATTN: CECW-PR

ATTN: CEMP

ATTN: CEMP-E

ATTN: CERD-C

ATTN: CERD-ZA

ATTN: CERD-L

ATTN: CERD-M (2)

ACS(IM) 22060

ATTN: DAIM-FDP

CECPW 22310-3862

ATTN: CECPW-E

ATTN: CECPW-FT

ATTN: CECPW-ZC

US Army Engr District

ATTN: Library (42)

US Army Engr Division

ATTN: Library (8)
US Army Materiel Command (AMC)

Alexandria, VA 22333-0001

ATTN: AMCEN-F

ATTN: AMXEN-C 61299-7190

Installations: (20)

FORSCOM

Forts Gillem \& McPherson 30330

ATTN: FCEN

Installations: (20)

TRADOC

Fort Monroe 23651

ATTN: ATBO-G

Installations: (20)

American Public Works Assoc. 64104-1806

US Gov't Printing Office 20401

ATTN: Rec Sec/Deposit Sec (2)

Defense Tech Info Center 22060-6218

ATTN: DTIC-O (2) 